\title{
O Conservadorismo Essencial como característica da psiquê das elites brasileiras: uma análise conceitual em Manoel Bomfim (1868-1932)
}

\author{
Patrick Silva dos Santos \\ Recebido em março de 2020 \\ Aceito em junho de 2020
}

\begin{abstract}
RESUMO
Uma das grandes narrativas que permearam o debate acadêmico no Brasil se dá em torno do processo civilizatório aqui construído junto ao colonizador português e a transplantação de suas instituições para o interior do Estado imperial brasileiro. As estruturas de poder patrimonialista estamental plasmada historicamente pelo Estado português para sua colônia americana, ainda hoje, são recuperadas como elemento explicativo das origens das mazelas brasileiras. Não me interessa aqui ratificar essa assertiva ou condená-la. O que me interessa é apresentar a explicação similar do médico Manoel Bomfim (1868 1932), que sem mobilizar o conceito de patrimonialismo de Max Weber -, em seu primeiro ensaio histórico-sociológico A América Latina: males de origem (1905), utiliza o conceito de conservadorismo essencial para explicar traços da herança portuguesa que se cristalizaram no modelo de atuação estatal e nas demais dinâmicas sociais brasileiras.
\end{abstract}

Palavras-chave: Manoel Bomfim; Conservadorismo Essencial; Herança portuguesa; Estado brasileiro; Patrimonialismo.

\section{The Essential Conservatism as a characteristic of the psyche of Brazilian elites: a conceptual analysis in Manoel Bomfim (1868-1932).}

\begin{abstract}
One of the great narratives that permeated the academic debate in Brazil is about the civilizing process built here with the Portuguese colonizer and the transplantation of its institutions to the interior of the Brazilian imperial state. The structures of state's patrimonialist power historically shaped by the Portuguese State for its American colony, even today, are recovered as an explanatory element of the origins of Brazilian ills. I am not interested in ratifying this assertion or condemning it. What interests me is to present the similar explanation to the doctor Manoel Bomfim (1868 - 1932) who, without mobilizing Max Weber's concept of patrimonialism -, in his first historical-sociological essay A América Latina: males de origem (1905) uses the concept of conservatism essential to explain traces of the Portuguese heritage that are crystallized in the model of state action and in other Brazilian social dynamics.
\end{abstract}

Keywords: Manoel Bomfim; Conservatism Essential; Portuguese heritage; Braziliam state; Patrimonialism.

\footnotetext{
${ }^{1}$ Doutorando em Sociologia. Pelo Programa de Pós-graduação em Sociologia (PPGS), da Universidade Federal Fluminense (UFF); mestre em Sociologia pela mesma instituição; graduado em Ciências Sociais pelas Faculdades Integradas Campograndense (FIC). Desde 2015 - Professor de Sociologia da Rede Estadual de Educação do Rio de Janeiro (SEEDUC/RJ) e Bolsista da CAPES. E-mail: patricksds@id.uff.br.
} 
$\mathrm{M}$ anoel José do Bomfim nasceu no ano de 1868, na província de Aracaju, no estado de Sergipe e veio a falecer no ano de 1932, no estado do Rio de Janeiro. Filho de Maria Joaquina do Bomfim e de Paulino José do Bomfim, um respeitado comerciante e dono de engenho de Aracaju, que havia sido vaqueiro durante a infância. Em 1891, Manoel Bomfim casou-se com a jovem portuguesa Natividade Aurora de Oliveira e, com ela, Bomfim teve dois filhos: Maria, que veio a falecer em 1894, com um ano e dez meses de idade, vitimada por uma epidemia de tifo e, em agosto do mesmo ano, nasceu seu filho Aníbal.

Manoel Bomfim foi um importante intelectual brasileiro da Primeira República, médico de formação que, em 1886 ingressou na Faculdade de Medicina da Bahia e, dois anos mais tarde, transferiu-se para a Faculdade de Medicina do Rio de Janeiro, onde se formou no ano de 1890. Todavia, a guinada de Bomfim para um caminho um pouco mais distante da medicina se deu no ano de 1902, quando foi montada uma comissão pedagógica nomeada pela prefeitura do Rio de Janeiro e, fazendo parte dessa comissão, Manoel Bomfim foi para Paris estudar psicologia na Sorbonne, sob a orientação de Alfred Binet, atuando como assistente de Binet junto a Georges Dumas.

Bomfim se notabilizou por sua atuação no campo educacional da Primeira República, tendo ocupado diversos cargos de importância: em 1896, foi nomeado pelo prefeito Francisco Furquim Werneck de Almeida o novo subdiretor do Pedagogium², tendo sido efetivado como diretor geral dessa instituição no ano seguinte; ainda em 1897, passa a lecionar na Escola Normal da República, tendo sido indicado para a cadeira de Moral e Cívica e, no ano seguinte, 1898, tornou-se diretor interino da Escola Normal; ainda em 1898 foi nomeado diretor de Instrução Pública do Distrito Federal (cargo ocupado por um ano), tendo exercido essa função em outras oportunidades;

\footnotetext{
${ }^{2}$ O Pedagogium - 1890-1919 - fundado no ano de 189o, por meio do decreto 667, de 16/08/189o, lavrado por Benjamin Constant, foi uma instituição educacional, onde desde 1911 funcionou o primeiro laboratório de psicologia experimental do Brasil, criado por Manoel Bomfim. Inicialmente funcionando na Rua Visconde do Rio Branco, 13, no centro da cidade do Rio de Janeiro - RJ. No ano de 1897 foi transferida para a Rua do Passeio, 66, também no centro da cidade, onde funcionou até seu fechamento, em 1919. Ver Gontijo (2010).
} 
lecionou na cadeira de Pedagogia e Psicologia Aplicada (ambas as disciplinas ministradas por ele na Escola Normal); em 1904, participou da criação da Upel Universidade Popular de Ensino Livre, juntamente com Elysio de Carvalho, Rocha Pombo, Fábio Luz, José Veríssimo entre outros, sendo essa Instituição de ensino superior de tendências anarquistas a única instituição de ensino superior em que Bomfim lecionou; em 1906, inaugura no Pedagogium o primeiro laboratório de psicologia experimental do Brasil e, em 1907 ele assume a vaga aberta na Câmara dos Deputados e, na condição de deputado federal pelo estado de Sergipe, buscou implementar alguns projetos por vias institucionais que acreditava serem indispensáveis para sanar os problemas relacionados à educação no país. No ano seguinte, buscou a reeleição e não conseguiu reeleger-se.

Contudo, após a apresentação do autor, o escopo deste artigo concentra-se em torno das discussões que permearam e, em alguma medida, ainda permeiam o debate acadêmico no Brasil: o processo civilizatório aqui construído durante séculos de exploração colonial portuguesa. Desta forma, umas das chaves investigativas é: a transplantação de suas instituições para o interior do Estado imperial brasileiro, e, por conseguinte, o Estado republicano, ou seja, a estrutura de poder patrimonialista estamental plasmada historicamente pelo Estado português para sua colônia americana, ainda hoje, é recuperado como elemento explicativo das origens das mazelas brasileiras. No entanto, o interesse central aqui é o conceito de conservadorismo essencial, de Manoel Bomfim (1868 - 1932) construído anteriormente ao conceito de patrimonialismo de Max Weber, aqui popularizado por Faoro (1977). Em suma, por meio deste conceito, Bomfim buscou explicar traços da herança portuguesa que se cristalizaram no modelo de atuação estatal e nas demais dinâmicas sociais brasileiras.

\section{Breve introdução - a América Latina: males de origem (1905)}

No ano de 1905 foi publicado pela editora francesa H. Garnier o primeiro ensaio histórico-sociológico de Manoel Bomfim, A América Latina: males de origem, cujas motivações do autor se potencializaram em razão da visão estereotipada dos 
europeus em relação às populações latino-americanas - e, também, pela aceitação desses "estigmas" por parte da intelectualidade brasileira e sul-americana formulados por meio da aceitação parcial e/ou adaptação das teorias deterministas raciais e geográficas, por parte significativa de seus contemporâneos, foi um dos elementos explicativos importantes em sua obra primeira, ao esclarecer os interesses de parte da intelectualidade ao tomar os determinismos como mecanismos primordiais para a explicação do atraso brasileiro. Portanto, Bomfim enxergou a tentativa de uma dupla dominação: a) no plano interno - das elites econômicas e intelectuais para com grande fração da população nacional e b) no plano externo - das nações centrais para com as nações periféricas. Assim, Bomfim entendeu as concepções científicas, tomadas por parte considerável dos seus contemporâneos, como uma falsa ciência, pois, para além de servir como instrumentos de dominação entre as classes, não se atestava a veracidade de determinados pressupostos, a partir de metodologias sérias e/ou passíveis de verificação de resultados concretos.

Nesse sentido, podemos compreender uma dimensão central motivacional e reflexiva de seu ensaio: desnudar a voga do período, mascarada de ciência, cuja intelectualidade do seu tempo tomava como o dogma explicativo do atraso nacional. As reflexões centrais e as anotações avulsas começam a ser feitas por Manoel Bomfim dez anos antes de sua publicação, já em 1897, quando ele era membro do Conselho Superior de Instrução Pública e, nesta condição, fez um parecer do livro didático História da América (1897), de Rocha Pombo -, nesse momento já existia um “embrião" do livro de Bomfim, e sua estadia na Europa, mais precisamente na França, só veio impulsionar a materialização em forma de livro de suas reflexões e anotações que já vinham sendo feitas anteriormente, no fim do século XIX (BOMFIM, 1905).

O livro A América Latina foi uma reação aos preconceitos dos europeus frente ao nosso continente e, em alguma medida, uma tentativa de dar-lhes a resposta e situar os verdadeiros culpados destes males. Em seu livro de 1931, Cultura e Educação do Povo Brasileiro - Pela diffusão da Instrucção Primaria, novamente Bomfim remonta essa dimensão motivacional para a execução do texto final de $A$ América Latina, assim retornando à questão: 
Passaram-se dois ou tres annos. Ingressei no magisterio. Tratei de prepararme para o exercicio das minhas funç̧ões, partindo para a Europa, afim de estudar psychologia experimental. No velho continente fui empolgado pela actividade da vida politica e social, ao ponto de reflectir-se em meus sentimentos toda aquella agitação. Todavia, doia-me muito a má reputação feita para a America do Sul e o Brasil, inclusive. Veio a reacção forte e impetuosa e assim escrevi A America Latina. Quem o lêr compreenderá e perceberá como entra alli o coração. Esse livro foi escripto sobretudo, para chegar a conclusão que lá está: os povos sul-americanos são victimas da formação colonial que tiveram. Sob esta causa desenvolveram-se os vicios que turbaram e vêm turbando a vida politica. Não ha nesses povos inferioridade essencial (BOMFIM, 1931, p. 71 et seq.).

Assim, A América Latina: males de origem foi produto cuja finalidade era a recuperação da autoimagem do continente, por muito difamada por meio de pressupostos que não condiziam com a realidade de nossa formação histórica e social e, não menos importante, a tentativa de apresentar o "remédio" para sanar os problemas que adquirimos, por meio de séculos de exploração colonial, que para ele, era o verdadeiro culpado do nosso "atraso", e não a constituição étnico-racial de grande parte das populações marginalizadas do continente sul-americano.

\section{A formulação de Manoel Bomfim - o conservadorismo essencial}

Em termos descritivos, o conceito de Conservadorismo Essencial, formulado por Manoel Bomfim em A América Latina: males de origem em 1905, mais se assemelha, do que propriamente se distancia das formulações conceituais de Max Weber em torno do Patrimonialismo, em sua maneira utilizada no Brasil, popularizado por meio do trabalho do jurista Raymundo Faoro, no livro Os Donos do Poder - Formação do Patronato Político Brasileiro, publicado em 19583. Faoro utilizou-se da concepção weberiana de patrimonialismo para explicar os problemas do Estado e da nação brasileira. Segundo ele, a estrutura de poder aqui transplantada

\footnotetext{
3 É importante deixar claro ao leitor que a comparação aqui estabelecida se concentra na utilização do patrimonialismo executada por Raymundo Faoro (1977). Isto é, ainda que o conceito de conservadorismo essencial de Manoel Bomfim anteceda o conceito de patrimonialismo de Max Weber Faoro utiliza o conceito de patrimonialismo como um conceito normativo, ao passo que o conceito em Weber possuí um caráter distintivo. Neste sentido, o conservadorismo essencial de Manoel Bomfim torna-se passível de aproximação ao uso do conceito de patrimonialismo "à brasileira" empregado por Raymundo Faoro. Pois o conceito de Bomfim, assim como o uso dado por Faoro ao conceito weberiano, são normativos.
} 
tinha o caráter patrimonialista estamental, que foi plasmada historicamente pelo Estado português para o Brasil por meio da transmigração da Corte portuguesa no início do século XIX. A organização do poder segundo essa abordagem tornou-se o padrão encrustado na estrutura do Estado brasileiro desde então.

Clássico da sociologia, o intelectual alemão Max Weber (1864-1920), ao formular o conceito de Patrimonialismo, que se subdivide em patrimonialismo estamental e patrimonialismo patriarcal, Weber o utilizou para contrastar uma forma distinta de atuação em contraposição à burocracia moderna. Assim, o complexo político patrimonial deve ser compreendido em oposição ao “sistema de 'autoridades' regulamentadas de forma geral por ordens objetivas e com deveres administrativos circunscritos e igualmente regulamentados" (Weber, 1999, p. 302). Deste modo, afirmava o autor, que a

[...] posição global do funcionário patrimonial é, portanto, em oposição à burocracia, produto de sua relação puramente pessoal de submissão ao senhor, e sua posição diante dos súditos nada mais é que o lado exterior desta relação. Mesmo ali onde o funcionário político não é pessoalmente um dependente da corte, o senhor exige sua obediência ilimitada no cargo. Pois a fidelidade ao cargo patrimonial não é uma fidelidade objetiva do servidor perante tarefas objetivas, cuja extensão e conteúdo estão delimitados por determinadas regras, mas, sim, uma fidelidade de criado que se refere de forma rigorosamente pessoal ao senhor e constitui uma parte integrante de seu dever de princípio universal de piedade e fidelidade (WEBER, 1999, p. 255).

Por isso, em Max Weber (1999) o funcionalismo patrimonial, ainda que, devido a sua progressiva divisão das funções racionalizadas e à formação de instâncias hierárquicas ordenadas, em alguma medida, pode assumir traços burocráticos. Ora, em "seu caráter sociológico, o cargo genuinamente patrimonial distingue-se tanto mais burocrático quanto mais puro se apresenta em cada um deles o respectivo tipo" (WEBER, 1999, p. 253). Então, na maneira de atuação patrimonial “falta sobretudo a distinção burocrática entre a esfera 'privada' e 'oficial”" (WEBER, 1999, p. 253). Isto é, nestes casos, “a administração política é tratada como assunto puramente pessoal do senhor, e a propriedade e o exercício de seu poder político, como parte integrante de seu patrimônio pessoal” (WEBER, 1999, p. 253).

Já o conservadorismo essencial é uma questão central em A América Latina: 
males de origem, pois é um elemento do caráter latino-americano, adquirido por meio da herança e educação transmitidas a nós por meio da relação mantida por séculos com os povos colonizadores do continente. O conservadorismo materializase como entrave para um projeto de modernização que não esteja alinhado ao passado. Todavia, a explicação para a força do conservadorismo descrito no ensaio histórico-sociológico do médico sergipano concentra-se na tentativa de atualização de privilégios ancorados nas tradições do passado, por isso, Manoel Bomfim salienta que, onde quer que surja uma forma de oposição conservadora, há um privilegio que quer-se manter, é por isso que este conservadorismo resiste pura e simplesmente ao progresso, que, no limite, destruiria as vantagens dos grupos dominantes, e, também, afrontaria certos preconceitos e superstições (BOMFIM, 1905).

Segundo Manoel Bomfim, a fundação das instituições coloniais, estas sendo cópias "perfeitas” das instituições das metrópoles ibéricas, perduram para além dos tempos coloniais, tendo seus efeitos reproduzidos nas sociedades latino-americanas após o fim do regime de exploração direta das metrópoles. Assim, o médico sergipano caracteriza essa comparação entre as instituições coloniais e metropolitanas:

As instituições sociaes eram a reproducção grosseira e viciada das instituições da peninsula: os feudos, representados nas fazendas e dominios mineiros; a servidão, na escravaria ignara, aviltada pelo tronco e o calabróte. A religião é o fetichismo, a superstição bronca; a familia é um pedaço de tribu, semi-feudal, semi-patriarchal, degradada pela ociosidade sobre o trabalho do negro, pervertida pelo espectaculo permanente dos barbaros tratamentos e castigos, infligidos ao escravo (BOMFIM, 1905, p. 152).

Já por meio do conservadorismo das elites encasteladas, na estrutura do Estado, Bomfim prosseguiu afirmando que:

[...] a politica vem a ser, não só ridiculamente absurda, como essencialmente criminosa, tratando-se de nações onde não ha, em verdade, o que conservar. A historia nos mostrará que, nas nacionalidades sul-americanas, antes mesmo de completa a independencia, já apparece um partido $<$ conservador $>$, pesando decisivamente sobre a marcha das cousas publicas. Pergunta-se agora: que é que havia então para conservar?... A vida das populações, a linguagem, os territorios?.. E' ainda hoje: em nome do que se justifica esse programma de politica conservadora?... São nações, estas, em que tudo está por fazer, a começar pela educação politica e social das populações. Que pretendem então defender, deste passado?... Elle é uma serie de crimes, iniquidades, violações de direitos, resistencias systematicas 
ao progresso (BOMFIM, 1905, p. 168).

Para Manoel Bomfim, o conservadorismo essencial tem sua efetividade no imaginário social de forma muitas vezes inconsciente, por isso, ao pensar a classe política latino-americana de um dado período histórico, ele observou que esse tipo específico de conservadorismo - traço psicológico e cultural - permitia compreender que aqui, até os grupos vinculados a tendências políticas revolucionárias seriam, por assim dizer, revolucionários "até a hora exacta de fazer a revolução, em quanto a reforma se limita ás palavras; no momento da execução, o sentimento conservador os domina e o proceder de amanhã é a contradicção formal, ás ideias" (BOMFIM, 1905, p. 174).

E, por que isso ocorria? Segundo Bomfim, isso ocorria porque, na "America do Sul, essa politica conservadora mais se aggrava porque é generalisada - para todos os partidos" (BOMFIM, 1905, p. 173), ou seja, a reprodução desta relação não ocorria "só por interesse, é por herança, por educação" (BOMFIM, 1905, p. 173). Portanto, por ser traço transmitido por vias de uma herança e educação colonial que sua manifestação é nítida nas mais variadas relações sociais destas sociedades. Por isso que Bomfim afirma que na América Latina "não é só no mundo politico que isto se nota. Estas sociedades são em geral archivos de instituições e costumes archaicos com etiquetas modernas" (BOMFIM, 1905, p. 176), para ele, "um glossario moderno designando um mundo obsoleto" (BOMFIM, 1905, p. 176).

\section{A psique das elites brasileiras segundo Manoel Bomfim}

O peso dessa herança portuguesa teve influência expressiva na formação brasileira. Se, por um lado, parte dessas populações tinham aversão ao Estado e às instituições burocráticas que exerciam funções sociais análogas aos tempos coloniais e imperial, as classes sociais que não detinham poder político e econômico viam na figura do Estado a de um inimigo -, por outro lado, o Conservantismo Essencial forjou uma sociabilidade que, no limite, atualizava elementos da ordem social passada. A república brasileira representada pela figura de seus partidários 
republicanos, blindou-se tendo como modelo "democrático" a limitação da participação popular nas decisões, e as classes dominantes disputavam o poder político entre elas mesmas, tendo como modus operandi práticas comuns às hegemonias fechadas 4 (DAHL, 2001).

Segundo Manoel Bomfim, as elites brasileiras se importavam em conservar seus privilégios, conquistar cada vez mais o poder político e apossar-se do aparelho governamental. Para esses grupos, o passado tinha um peso ainda mais arrebatador, pois

\begin{abstract}
As classes dirigentes, herdeiras directas, continuadoras indefectiveis das tradições governamentaes, politicas e sociaes do Estado-metropole, parecem incapazes de vencer o peso dessa herança; e tudo que o parasitismo peninsular incrustou no caracter e na intelligencia dos governantes de então, aqui se encontra nas novas classes dirigentes; qualquer que seja o individuo, qualquer que seja o seu ponto de partida e o seu programma, o traço iberico lá está - o conservantismo, o formalismo, a ausencia de vida, o tradicionalismo, a sensatez conselheiral, um horror instinctivo ao progresso, ao novo, ao desconhecido, horror bem instinctivo e inconsciente, pois que é herdado (BOMFIM, 1905, p. 396).
\end{abstract}

O médico e professor sergipano enxergava o ideal republicano e a república brasileira de sua época como uma construção social falsa e excludente, além de uma abstração, da qual os "desastres e os males procedem unicamente de que elles" (BOMFIM, 1905, p. 410), isto é, as elites republicanas "pregam a liberdade, e não promovem os meios de tornal-a effectiva” (BOMFIM, 1905, p. 410). Por exemplo, Manoel Bomfim expõe a adoção do voto dos alfabetizados inserida pela Constituição dos Estados Unidos do Brasil de 1891 para criticar a não promoção dos meios para tornar a liberdade efetiva para todos os segmentos sociais. No limite, a Constituição brasileira do período restringiu os direitos políticos de $90 \%$ da população brasileira.

Comprehende-se, por ventura, uma democracia donde 90 por 100 dos individuos são excluidos por analphabetos? Tanto vale dizer: uma democracia sem povo, sem cidadãos. Um tal regimen, ainda que o levassem a uma pratica de pureza ideal, não passaria da oppressão e despotismo de

\footnotetext{
${ }^{4}$ Na Ciência Política norte-americana, as Hegemonias Fechadas foram descritas como regimes em que os participantes pelo poder político são baixos e/ou restritos, do ponto de vista, dos que podiam/podem tornar-se atores políticos elegíveis. E, por outro lado, a participação política da população nesse processo era/é limitada.
} 
uma aristocracia, sem nobreza, sobre a plebe servil. Não se trata de fazer o libello dos politicos; basta, para aquelles que são de boa fé, a tristeza de contemplar a propria obra, e vêr como esses oitenta annos de democracia na America latina têm desmoralisado o regimen e os ideaes que elles sinceramente apregoavam (BOMFIM, 1905, p. 409).

A tradição, a herança societária colonial, segundo a argumentação de Manoel Bomfim, teve um peso inigualável no caráter psicológico das elites brasileiras e, por conseguinte, nas relações sociais aqui estabelecidas entre as diferentes classes sociais e/ou os diferentes grupos étnico-raciais. Foi neste momento, sustenta o autor, que as Teorias Racialistas 5 se tornaram o novo dogma que mediava as relações sociais em solo brasileiro (BOMFIM, 1905; SCHWARCZ, 1993). Portanto, setores significativos, por meio deste instrumento teórico, estigmatizavam grande parte da população e mantinham-se no topo da hierarquia social.

A apologia da imigração europeia e, acessoriamente, a exclusão de setores populacionais cujas constituições étnico-raciais escapavam o modelo societário no qual o Brasil buscava inserir-se, foi objeto de análise crítica de Manoel Bomfim em seu ensaio A América Latina: males de origem. O afastamento das populações negras e mestiças das regiões centrais da capital brasileira foi planejado e executado por setores das elites políticas que buscavam afastar-se do seu passado colonial e, sobretudo, operacionalizar tal projeto implicava em excluir quem outrora foi responsável pelo trabalho que enriqueceu cada vez mais tantos senhores de engenho, barões do café, traficantes de escravos, donos de minas de pedras preciosas, ouro e prata, e assim sucessivamente.

Neste sentido, o traço psicológico das classes dirigentes brasileiras analisadas pelo médico sergipano foi o desprezo sistemático pelos indivíduos cujas marcas da pele indicavam as lembranças de um passado marcado pelo trabalho compulsório. Revitalizar o passado fazia-se necessário na psique desses grupos que dominavam

\footnotetext{
${ }^{5}$ Lilia Schwarcz (1993) afirma que muitos dos intelectuais que tiveram atuação nas faculdades brasileiras nos séculos XIX e no início do século XX tinham no seu fazer ciência uma espécie de espelho das teorias racialistas do continente europeu, assim, reproduzindo em seus estudos sobre a gênese do povo brasileiro os estigmas e preconceitos em relação à miscigenação dessa população. Muitos "homens de ciência" brasileiros, dos fins do século XIX e início do século XX, atuaram como publicistas das teorias deterministas europeias que justificavam as ações perpetradas pelos imperialismos europeus e norteamericanos, além de auxiliar, em última análise, a difundir uma concepção pessimista sobre o presente e o futuro brasileiro e dos demais países da América do Sul.
} 
nacionalmente as mais variadas dimensões de poder e reprodução da vida social daquela sociedade. Deste modo, a operação resumia-se em revitalizar os bônus e privilégios do passado e mascarar e/ou negligenciar os elementos do passado que deveriam ser esquecidos. Estes foram, segundo Manoel Bomfim, os traços marcantes das classes dominantes política e econômicas brasileiras dos primeiros anos republicanos.

\section{Conclusão}

A ideia deste artigo foi a de apresentar o conceito de Conservadorismo Essencial, sendo este fundamento, segundo Manoel Bomfim, explicativo de uma espécie de atitude mental compartilhada pelas populações egressas de sociedades que durante séculos conviveram sob a égide de um sistema de exploração colonial. Além disso, outro ponto desta dinâmica expositiva foi salientar as similaridades com o conceito de patrimonialismo, do sociólogo alemão Max Weber, operacionalizado por Raymundo Faoro (1977). Entretanto, assim como o conceito de Instituições Totais, do sociólogo canadense Erving Goffman, e o conceito de Ambiente Tuberculoso, do sociólogo brasileiro Oracy Nogueira (que foi orientado pelo sociólogo da segunda geração da Escola de Chicago, Donald Pierson), ambos os conceitos concorrentes sem necessariamente terem sido formulados por meio de análises de um ou outro e viceversa. O mesmo ocorreu com os conceitos de Manoel Bomfim e Max Weber. ${ }^{6}$

Digamos que o conceito de conservadorismo essencial possuí vitalidade explicativa para demonstrar a operacionalização de Teorias por parte das elites políticas e econômicas visando negar uma igualdade de cidadania comum a todos (na teoria) nas sociedades cujo ordenamento social é competitivo. Isto porque, numa sociedade estratificada em Classes Sociais, a utilização de hierarquias raciais para

\footnotetext{
6 Ressaltando que o conservadorismo essencial se aproxima analiticamente do patrimonialismo ressignificado por Raymundo Faoro.
} 
estratificar indivíduos ou grupos sociais é uma "doença”7 (DUMONT, 1974) incompatível com a nova ordem estabelecida após a desintegração do Estado imperial.

Então, a manutenção de privilégios comuns à ordem estamental numa sociedade de classes pode ser lida e interpretada por meio do Conservadorismo Essencial, traço pujante desse mindset compartilhado pelas classes dominantes brasileiras. Entretanto, o Estado brasileiro dos primeiros anos republicanos tem nas suas instituições a imagem e semelhança das instituições portuguesas? Aqui reside uma questão espinhosa que ainda hoje permeia o imaginário acadêmico brasileiro. Não podemos perder de vista que, assim que foi proclamada a República no Brasil, em 1889, houve uma tentativa ligeira de apagar os símbolos que remetessem ao nosso passado luso-brasileiro. Da mesma forma que, um ano após a Proclamação da República, houve uma tentativa de apagar séculos de escravidão negra da história oficial brasileira. A sociabilidade compartilhada pelas elites intelectuais, políticas e econômicas da Primeira República buscou agir de maneira similar com os traços portugueses. Símbolo de uma pretensa sociedade moderna, deveria estar alinhada às vogas francesas e estadunidenses (PRADO, 1895). Portanto, vincular-se às tradições e à cultura de Portugal era tomado como algo degradante para aquela sociedade brasileira recémrepublicana.

Manoel Bomfim foi um ator social e teve suas ambiguidades. Homem de um tempo, enxergou os problemas de sua época com os instrumentos analíticos acessíveis ao período, ainda que tenha produzido interpretações sobre o Brasil distintas de parte significativa de seus contemporâneos. Deixou de participar de instituições de consagração, como por exemplo, o Instituto Histórico e Geográfico Brasileiro (IHGB) e da Academia Brasileira de Letras (ABL), para esta última, ele foi convidado para ser um dos fundadores por alguns amigos ilustres, onde se destacava o bruxo do Cosme Velho, Machado de Assis. Inclusive, a pedido de Machado, Manoel Bomfim emprestou o espaço do Pedagogium para funcionar a ABL até a construção do prédio atual; já no caso do IHGB, Bomfim recusou porque era contrário à História oficial que era produzida pela instituição. Contraditoriamente ou não, foi diretor de

\footnotetext{
7 Em sociedades que se intitulam democráticas ou, no limite, próximas disto, a manutenção de hierarquias sociais pensadas, a partir de critérios raciais, constitui-se algo irracional, nos termos de Louis Dumont, "uma doença".
} 
Instrução Pública da administração do prefeito Pereira Passos, responsável pela remodelação, modernização e reorganização da cidade do Rio de Janeiro, que afastou os agentes sociais cujos caracteres econômicos e raciais não condiziam com uma sociabilidade em que o Brasil queria se inserir. Bomfim foi um ator social que esteve atento às transformações de seu tempo e buscou interpretar o Brasil que ele via transformando-se aceleradamente diante de seus olhos. Como sugeriu o sociólogo brasileiro Antonio Candido, (1990), Manoel Bomfim foi um dos intelectuais

[...] mais originais e clarividentes que o Brasil teve em relação a problemas que no seu tempo eram propostos e estudados de maneira insatisfatória como a nossa formação histórica, teor do nosso povo, a questão racial, a tendência conservadora das elites, o imperialismo norte-americano, etc. (CANDIDO, 1990, p. 10).

Em A América Latina: males de origem, o médico Manoel Bomfim abordou todos estes temas expostos na citação acima de Antonio Candido. E Bomfim foi além, como sugeriu o antropólogo, Darcy Ribeiro (1993):

Só muitas gerações depois as interpretações magistrais de Manoel Bomfim entraram em curso, lidas todas em outros autores. Muito antes de Gilberto Freyre aprender isto em Nova Iorque - como a sabedoria mais sábia da Universidade de Colúmbia - Manoel Bomfim dizia com toda clareza que as taras do crioléu não vinham da raça, mas da escravidão [...] Caio Prado ainda estava nascendo quando Manoel Bomfim nos falava com exatidão do caráter classista, intrinsicamente tirânico e espoliativo, do Estado brasileiro, por isso mesmo, justamente odiado ontem e hoje pelo povo. Também antes do que qualquer outro, Manoel Bomfim nos deu o diagnóstico do racismo como a técnica ideológica européia de dominação e escravização. O próprio Gilberto, quando retoma essas teses, trinta anos depois, o faz torpemente, encantado que estava com a bondade do senhor de engenho. Até o reconhecimento dos méritos do português como povo com grande capacidade de assimilação e de adaptação é assinalado por Manoel Bomfim, que o faz sem cair nos tropicalismos coloniais de Gilberto. [...] Multiplicaram-se, depois de Gilberto, os autores que se acercavam da visão de Manoel Bomfim, tais como Arthur Ramos, Josué de Castro, Sérgio Buarque, Caio Prado. Nenhum deles, porém, o leu (RIBEIRO, 1993, p. 15).

Com os devidos cuidados tomados no que concerne às limitações temporais do

autor. Manoel Bomfim apresentou em 1905, para o Brasil, pressupostos que representavam a fundação de uma barreira imaginária entre o pensamento hegemônico da intelectualidade brasileira e as suas teses originais para a época, muito 
utilizadas posteriormente por outros intelectuais brasileiros, ainda que estes não o tenham lido e/ou citado diretamente.

\section{Referências}

AGUIAR, Ronaldo Conde. O rebelde esquecido: tempo, vida e obra de Manoel Bomfim. Rio de Janeiro: ANPOCS/Topbooks, 2000.

ALVES FILHO, Aluizio. Pensamento político no Brasil - Manoel Bomfim: um ensaísta esquecido. Rio de Janeiro: Achiamé, 1979.

BOMFIM, Manoel. A America Latina: males de origem. Paris: H. Garnier, 1905.

Cultura e educação do povo brasileiro. Rio de Janeiro: Pongetti, 1931.

As fórmulas livrescas. In: PEREIRA, Gabriel Victor do Monte; SILVA, Menoel Cicero Peregrino da; et al (orgs). Biblioteca Internacional de Obras célebres - v. XXIV. 3. ed. Lisboa: Sociedade Internacional, sd, p. 11831-11841.

BOTELHO, André; SCHWARCZ, Lilia Moritz (org). Um enigma chamado Brasil - 29 intérpretes e um país. São Paulo: Companhia das Letras, 2009.

CANDIDO, Antonio. Radicalismos. Estudos Avançados, São Paulo, 4(8), 1990, p. 5-18.

CARVALHO, José Murilo de. Os Bestializados: o Rio de Janeiro e a república que não foi. 3. ed. São Paulo: Companhia das Letras, 1998.

DAHL, Robert A. Sobre a democracia. Brasília: UnB, 2001.

DUMONT, Louis. Casta, racismo e estratificação. In: AGUIAR, Neuma (org). Hierarquias em Classes. Rio de Janeiro: Zahar, 1974.

ELIAS, Norbert. O processo civilizador: uma história dos costumes. v. I. 2. ed. Rio de Janeiro: Zahar, 2011.

FAORO, Raymundo. Os donos do poder - formação do patronato político brasileiro. 4. ed. Porto Alegre/RS: Globo, 1977.

GOFFMAN, Erving. Manicômios, prisões e conventos. 8. ed. São Paulo: Perspectiva, 2008.

GONTIJO, Rebeca. Manoel Bomfim. Recife: Fundação Joaquim Nabuco/Massangana, 2010. 
NOGUEIRA, Oracy. Vozes de Campos do Jordão. São Paulo: Revista Sociologia, 1950.

PRADO, Eduardo. A Illusão Americana. 2. ed. Paris: Armand Colin et cie, Editeurs, 1895 .

RIBEIRO, Darcy. Manoel Bomfim, antropólogo. In: BOMFIM, Manoel. América Latina: males de origem. 3. ed. Rio de Janeiro: Topbooks, 1993.

SCHWARCZ, Lilia Moritz. O Espetáculo das Raças: cientistas, instituições e questão racial no Brasil 1870 - 1930. São Paulo: Companhia das letras, 1993.

; STARLING, Heloisa M. Brasil: uma biografia. São Paulo: Companhia das Letras, 2015 .

WEBER, Max. Economia e Sociedade: fundamentos da sociologia compreensiva volume 2. Brasília: UnB, 1999. 